Full length article

\title{
Infant sleep-wake behaviors at two weeks, three and six months
}

\author{
Bárbara Figueiredo ${ }^{\mathrm{a}, *}$, Cláudia Castro Dias $^{\mathrm{a}}$, Tiago Miguel Pinto ${ }^{\mathrm{a}}$, Tiffany Field ${ }^{\mathrm{b}}$ \\ a School of Psychology, University of Minho, Braga, Portugal \\ b University of Miami School of Medicine, Miami, USA
}

\section{A R T I C L E I N F O}

\section{Article history:}

Received 13 October 2015

Received in revised form 10 June 2016

Accepted 23 June 2016

\section{Keywords:}

Infant sleep-wake behaviors

Infant sleep-wake development

Infant individual change

Infant individual stability

\begin{abstract}
A B S T R A C T
Although infant sleep-wake behavior presents several developmental changes during the first six months, literature lacks on reference values and few studies have explored the role of individual change and stability on infant sleep-wake behavior during the first six months. This study aimed (1) to describe infant sleep-wake behaviors during the 24-h period, day and night, at two weeks, three, and six months, (2) and to explore developmental changes and the role of individual change and stability on infant sleep-wake behaviors from two weeks to six months. Ninety-four primiparous mothers completed measures on infant sleep-wake behaviors at two weeks, three and six months. Significant developmental changes were found on infant sleep-wake behaviors from two weeks to six months. Twoweek-old infants sleep $13.3 \mathrm{~h}$, spend $8.7 \mathrm{~h}$ awake, awake 6.1 times, have $0.4 \mathrm{~h}$ of latency to sleep, and $3.2 \mathrm{~h}$ of longest sleep period. Three-month-old infants sleep $13.0 \mathrm{~h}$, spend $9.2 \mathrm{~h}$ awake, awake 5.5 times, have $0.4 \mathrm{~h}$ of latency to sleep, and $5.2 \mathrm{~h}$ of longest sleep period. Sixmonth-old infants sleep $12.2 \mathrm{~h}$, spend $10.0 \mathrm{~h}$ awake, awake 5.2 times, have $0.4 \mathrm{~h}$ of latency to sleep, and $5.6 \mathrm{~h}$ of longest sleep period. Significant individual change and stability were also found on infant sleep-wake behaviors from two weeks to six months. Despite significant developmental and individual changes, individual stability explains a significant amount of the variance on infant sleep-wake behaviors over the first six months of life.
\end{abstract}

(c) 2016 Elsevier Inc. All rights reserved.

\section{Introduction}

The development of sleep-wake behavior is a major maturational process during the first year of life, associated with infant neurobehavioral organization, temperament and cognitive functioning (e.g., Henderson, France, Owens, \& Blampied, 2010), and informing about infant health and well-being (e.g., Montgomery-Downs \& Gozal, 2006; Scher, Zukerman, \& Epstein, 2005; Taveras, Rifas-Shiman, Oken, Gunderson, \& Gillman, 2008). Sleep developmental problems affect between 15-35\% of infants $^{1}$ and are major concerns to clinicians and parents (Byars, Yolton, Rausch, Lanphear, \& Beebe, 2012; Mindell, Meltzer, Carskadon, \& Chervin, 2009; Mindell, Sadeh, Wiegand, How, \& Goh, 2010). However, only few studies provided reference values and little is known about individual change and stability on infant sleep-wake behaviors during the first six months of life (e.g., Freudigman \& Thoman, 1993; Magee, Gordon, \& Caputi, 2014; Scher, Epstein, \& Tirosh, 2004).

\footnotetext{
* Corresponding author.

E-mail addresses: bbfi@psi.uminho.pt (B. Figueiredo), cdias@psi.uminho.pt (C.C. Dias), tmpinto@psi.uminho.pt (T.M. Pinto), tfield@med.miami.edu (T. Field).

${ }^{1}$ Due to several cross-cultural differences in infant sleep-awake behaviors (Mindell et al., 2010), only data from occidental countries are presented.
} 
One-month-old infants have averaged between 12.1 and $14.6 \mathrm{~h}$ of sleep time during the 24-h period (e.g., MontgomeryDowns \& Gozal, 2006; Quillin, 1997; Tikotzky \& Sadeh, 2009), ranging between 9 and 19h (Iglowstein, Jenni, Molinari, \& Largo, 2003). They have averaged $3.3 \mathrm{~h}$ of sleep during the day (Montgomery-Downs \& Gozal, 2006), with a range of between 0.5 and $9 \mathrm{~h}$ (Iglowstein et al., 2003; Montgomery-Downs \& Gozal, 2006). They have averaged $5.7 \mathrm{~h}$ of sleep during the night (Montgomery-Downs \& Gozal, 2006), ranging between 5 and 14 h (e.g., Iglowstein et al., 2003; Montgomery-Downs \& Gozal, 2006). One-month-old infants spend an average of $2.4 \mathrm{~h}$ awake during the night (Tikotzky \& Sadeh, 2009). At 0-2 months, the average awake time during the night was $1.2 \mathrm{~h}$ (Sadeh, Mindell, Luedtke, \& Wiegand, 2009; Teng, Bartle, Sadeh, \& Mindell, 2012). One-month-old infants have averaged 5.3 awakenings during the 24-h period (Montgomery-Downs \& Gozal, 2006), between 3.1 and 3.3 awakenings during the day (e.g., Matthey, 2001; Montgomery-Downs \& Gozal, 2006), and between 2 and 4 during the night (e.g., Burnham, Goodlin-Jones, Gaylor, \& Ander, 2002; Goodlin-Jones, Burnham, Gaylor, \& Anders, 2001; Montgomery-Downs \& Gozal, 2006). At 0-2 months, they wake 5.5 times during the 24-h period, 3.6 times during the day and 1.9 times during the night (Mindell et al., 2010; Sadeh et al., 2009). Moreover, they have averaged 32 min of latency to sleep during the day (Matthey, 2001), and between 23 and 40.3 min during the night (Matthey, 2001; Tikotzky \& Sadeh, 2009). Infants were found to have a longest sleep period during the night of between 3 and 4.1 h at one month (Anders \& Keener, 1985; Burnham et al., 2002; Goodlin-Jones, Eiben, \& Anders, 1997), with an average of 3.6 h reported in a recent review (Henderson, France, \& Blampied, 2011).

Different averages of sleep time during the 24-h period have been reported for three-month-old infants - from 12.8 to 13.6 h (Bruni et al., 2014; Galland, Taylor, Elder, \& Herbison, 2012; Harrison, 2004), ranging from 10 to 19 h (Iglowstein et al., 2003). Three-month-old infants were found to sleep between 3.3 and $3.5 \mathrm{~h}$ during the day (Bruni et al., 2014; Tikotzky et al., 2015), ranging from 1 to $8 \mathrm{~h}$ (Iglowstein et al., 2003). During the night, they averaged between 9.4 and $9.5 \mathrm{~h}$ (Bruni et al., 2014; Tikotzky et al., 2015), ranging from 7 to $13 \mathrm{~h}$ (Iglowstein et al., 2003). At 3-5 months infants were found to be awaken, in average, $0.5 \mathrm{~h}$ during the night (Mindell et al., 2010; Sadeh et al., 2009; Teng et al., 2012). At three months, infants have averaged 3.4 awakenings/sleep periods during the day (Bruni et al., 2014), and between 2.5 and 2.9 times during the night (e.g., Burnham et al., 2002; Goodlin-Jones et al., 2001; Tikotzky et al., 2015). At 3-5 months, infants sleep between 4.2-4.4 periods during the 24-h period, between 2.9 and 3.1 during the day and between 1.2 and 1.3 during the night (Mindell et al., 2010; Sadeh et al., 2009; Teng et al., 2012). Three-month-old infants were found to have a longest sleep period during the night of between 4.7 and 6 h (Anders, Halpern, \& Hua, 1992; Burnham et al., 2002; Goodlin-Jones et al., 2001). A recent review stated that the average longest sleep period during the night is $5.5 \mathrm{~h}$ at three months (Henderson et al., 2011).

Six-month-old infants sleep an average of between 12.6 and $14.2 \mathrm{~h}$ during the 24 -h period, with their total sleep ranging between 6.5 and $18 \mathrm{~h}$ (e.g., Blair et al., 2012; Iglowstein et al., 2003; Montgomery-Downs \& Gozal, 2006). They averaged between 2.3 and $3.1 \mathrm{~h}$ during the day (Bruni et al., 2014; Tikotzky et al., 2010, 2015), ranging between 0.2 and $6.5 \mathrm{~h}$ (Iglowstein et al., 2003; Montgomery-Downs \& Gozal, 2006). During the night, six-month-old infants sleep an average of 9.5-11 h (Bruni et al., 2014; Iglowstein et al., 2003; Tikotzky et al., 2010), ranging from 5 to 15.5 h (Iglowstein et al., 2003; MontgomeryDowns \& Gozal, 2006). Six-month-old infants have averaged 0.7 h awake during the night (Tikotzky \& Sadeh, 2009) and 0.4 h at 6-8 months (Sadeh et al., 2009; Teng et al., 2012). Literature have been reported an average of 3.6 awakenings during the 24-h period at 6 months (Montgomery-Downs \& Gozal, 2006), between 2.6 and 2.8 awakenings during the day (e.g., Bruni et al., 2014; Matthey, 2001; Montgomery-Downs \& Gozal, 2006), and between 1 and 3.5 awakenings during the night (e.g., Burnham et al., 2002; Goodlin-Jones et al., 2001; Montgomery-Downs \& Gozal, 2006; Tikotzky et al., 2015). At 6-8 months, infants were found to have 3.7-3.9 sleep periods during the 24-h period, 2.5-2.6 during the day, and 1.3 during the night (Mindell et al., 2010; Sadeh et al., 2009; Teng et al., 2012). They have averaged 11 min of latency to sleep during the day (Matthey, 2001), and between 12 and 21.5 min during the night (Matthey, 2001; Tikotzky \& Sadeh, 2009). Moreover, at six months, infants have a longest sleep period during the night of between 4.8 and $7.1 \mathrm{~h}$ (Anders \& Keener, 1985; Burnham et al., 2002; Goodlin-Jones et al., 2001). In their review, Henderson et al. (2011) also stated that the average longest sleep period during the night is $5.8 \mathrm{~h}$ at six months.

The association between infant sleep-awake behaviors during the day and the night has been poorly explored. Previous studies on infant sleep-awake behaviors during the day and the night have focused on differences. No differences were found on infant sleep-awake behaviors during the day before two months, namely on sleep hours and time out of the crib (Ingersoll \& Thoman, 1999), while at three months sleep hours during the night are almost the double of sleep hours during the day (Parmalee, Wenner, \& Schulz, 1964).

To discriminate between day and night and to concentrate sleep hours during the night and awake hours during the day are major developmental processes during the first year of infant's life (Sadeh, 2000). A significant decrease on the number of sleep hours during the 24 -h period has been reported during the first six months (e.g., Sadeh et al., 2009; Teng et al., 2012; Tikotzky \& Sadeh, 2009). Infants start to concentrate their sleep during the night, presenting a decrease on the number of sleep hours during the day (Sadeh et al., 2009; Teng et al., 2012; Tikotzky et al., 2015), accompanied by an increase on the number of sleep hours during the night (e.g., Parmalee et al., 1964; Sadeh et al., 2009; Teng et al., 2012; Matthey, 2001).

Infants become able to get and return to sleep without help, presenting a significant decrease on the latency to sleep during the day and the night during the first six months (Matthey, 2001; Tikotzky \& Sadeh, 2009). During this period infants also become able to sleep through the night, presenting a significant increase on the longest sleep period (Burnham et al., 2002; Goodlin-Jones et al., 1997; Teng et al., 2012), accompanied by a decrease on the awakenings during the night (e.g., Sadeh et al., 2009; Teng et al., 2012; Tikotzky \& Sadeh, 2009) and a decrease on the number of awake hours during the night (e.g., Sadeh et al., 2009; Teng et al., 2012; Tikotzky \& Sadeh, 2009). 
Table 1

Socio-demographic characteristics.

\begin{tabular}{|c|c|c|c|c|}
\hline & & & \multicolumn{2}{|c|}{$N=94$} \\
\hline & & & $\mathrm{N}$ & $\%$ \\
\hline \multirow[t]{11}{*}{ Mother } & Age & $18-29$ & 33 & 31.1 \\
\hline & & $30-39$ & 57 & 60.6 \\
\hline & & $\geq 40$ & 4 & 4.3 \\
\hline & Ethnicity & Caucasian & 90 & 97.8 \\
\hline & & Other & 1 & 2.2 \\
\hline & Matrimonial status & Married/cohabiting & 78 & 83.0 \\
\hline & & Single/divorced/widow & 16 & 17.0 \\
\hline & Occupational status & Employed & 74 & 78.7 \\
\hline & & Unemployed/Household/student & 20 & 21.3 \\
\hline & Years of schooling & $\leq 12$ & 25 & 26.6 \\
\hline & & $>12$ & 69 & 73.4 \\
\hline \multirow[t]{4}{*}{ Pregnancy and delivery } & Reanimation at birth & No & 89 & 94.7 \\
\hline & & Yes & 5 & 5.3 \\
\hline & Type of delivery & Vaginal & 44 & 46.8 \\
\hline & & Caesarean & 50 & 53.2 \\
\hline \multirow[t]{4}{*}{ Infant } & Sex & Female & 40 & 42.6 \\
\hline & & Male & 54 & 57.4 \\
\hline & Ponderal index & $<2.5$ & 8 & 8.5 \\
\hline & & $\geq 2.5$ & 86 & 91.5 \\
\hline
\end{tabular}

Individual differences on infant sleep-wake behaviors were reported over the first six months, as indicated by high standard deviations (e.g., Bruni et al., 2014; Burnham et al., 2002). Individual differences on infant sleep-wake behaviors at two weeks were also seen to explain a significant amount of infant sleep-wake behaviors differences at nine months, and explain more variance than change on infant sleep-wake behaviors from two weeks to nine months (St James-Roberts \& Plewis, 1996). Moreover, high individual stability on infant sleep-wake behaviors during the first six months was also reported with significant correlations found between infant sleep onset time, transitions from sleep to wake, longest sleep period, and sleep efficiency from three to six months (Scher et al., 2004).

Infant sleep-wake behavior presents several developmental changes during the first six months, however literature lacks on reference values to guide clinicians, parents and researchers (e.g., Freudigman \& Thoman, 1993; Magee et al., 2014; Scher et al., 2004). Likewise, the role of individual change and individual stability on infant sleep-wake behavior over the first six months of life has also been poorly explored. Addressing these gaps in literature, this study aimed to (1) describe infant sleep-wake behaviors during the day and the night, at two weeks, three, and six months, and (2) to explore developmental changes and the role of individual change and stability on infant sleep-wake behaviors from two weeks to six months.

\section{Methods}

\subsection{Participants}

The sample was comprised of 94 infants. All infants were first-born, full-term, of normal birth weight ( $\geq 2500 \mathrm{~g})$ and had no health problems (no hospitalization or admission to the intensive care unit in the first two weeks post-birth). The majority of the mothers were Caucasian (97.8\%), married or cohabiting (83\%), and employed (78.7\%). More than a half were aged between 30 and 39 years old (60.6\%), and had more than 12 years of schooling (73.4\%). The majority of the infants were not reanimated at birth (94.7\%), and had a normal ponderal index ( $\geq 2.50 ; 91.5 \%)$. More than a half of the infants were male $(57.4 \%)$ and born by caesarean delivery (52.3\%). More than a half of the infants (56.3\%) were not bed sharing with the mother, while $43.7 \%$ bed shared (18.3\% daily, $15.5 \%$ more than once a week, and $9.9 \%$ once a week). The majority of the infants $(81.9 \%)$ were exclusively breastfed at two weeks, $68.1 \%$ at three months, and $4.3 \%$ at six months; $17 \%$ were partially breastfed at two weeks and three months, and $60.6 \%$ at six months; and $1.1 \%$ were exclusively artificial fed at two weeks, $14.9 \%$ at three months, and $35.3 \%$ at six months (Table 1 ).

\subsection{Procedure}

The Ethical Commissions of University of Minho and Centro Hospitalar do Porto approved the research protocol. One hundred eighty five pregnant women were contacted at the hospital during the third trimester, informed about the purposes and procedures of the study and invited to participate. Women who did not read or write Portuguese, multiparas and multiple births were excluded. Women who agreed to participate (90\%) signed an informed consent. The mothers completed on-line measures of socio-demographic data and infant sleep-wake behaviors at two weeks $(M=3.32$ weeks, $S D=2.39)$, three $(M=14.01$ weeks, $S D=1.93)$ and $\operatorname{six}(M=28.27$ weeks, $S D=3.60)$ months postpartum. Twenty-five participants were excluded: six preterm infants, three infants with low birth weight and 16 infants who were admitted to the intensive care 
unit during the first two weeks of life. Of the 141 mothers who completed measures of socio-demographic data and infant sleep-wake behaviors at two weeks, 94 (67.0\%) completed the same measures at three and six months, and were included in the data analyses. The group that completed all the assessments and was included in the analyses and the group that did not complete all the assessments and was not included in the analyses did not differ on: mother's age, matrimonial status, and occupational status, infant's reanimation at birth, type of delivery, sex, ponderal index, and sleep arrangement. Groups only differed on mother's years of schooling, $\chi^{2}(1)=11.45, p=0.001$, and feeding method at two weeks, $\chi^{2}(2)=9.37, p=0.009$, with the group that completed all assessments presenting higher education and higher rates of exclusive breastfeeding.

\subsection{Measures}

\subsubsection{Socio-demographic data}

Socio-demographic data were collected using a Socio-demographic Questionnaire. This questionnaire on social, demographic and obstetric information included gender, birth weight and length, gestational age, delivery mode, hospitalization, and breastfeeding status.

\subsubsection{Infant sleep-wake behaviors}

The Infant Sleep Chronogram was designed for this study for the mothers to record infant sleep-wake behaviors over a 24-h period. It is a timeline comprised of 30-min periods from 8 a.m. one day to 8 a.m. the next day. "Daytime" was defined as 8 a.m. to 8 p.m. and "nighttime" as 8 p.m. to 8 a.m. Based on the mothers' records, the following variables were coded for 24 -h period, day, and night: sleep hours, awake hours, awakenings, latency to sleep, and longest sleep period. 24-h period sleep, awake and awakenings were coded by the sum of the day and night, while the longest sleep period during the 24-h period was coded using the longest sleep period over the $24 \mathrm{~h}$. Latency to sleep was coded by the average number of hours the infant took to fall asleep for each sleep period during the 24-h period, the day and the night. In the present sample, the Infant Sleep Chronogram had acceptable internal consistency at two weeks (Cronbach's $\alpha=0.71$ ), at three months (Cronbach's $\alpha=0.62$ ), and at six months (Cronbach's $\alpha=0.63$ ).

\subsection{Statistical analyses}

In order to describe infant sleep-wake behaviors during the 24-h period, day and night, at two weeks, three, and six months, two repeated measures MANOVAs were performed. The first repeated measures MANOVA included sleep hours, awake hours, awakenings, latency to sleep, and longest sleep period (24-h period) as dependent variables with two weeks, three and six months as the repeated measures. The second repeated measures MANOVA included sleep hours, awake hours, awakenings, latency to sleep, and longest sleep period (day and night) as dependent variables with two weeks, three and six months as the repeated measures. In order to analyze associations between infant sleep-wake behaviors during the day and during the night at two weeks, three and six months, Pearson correlations were performed.

In order to analyze developmental changes and individual change and stability on sleep-wake behaviors from two weeks to six months, growth curve models were estimated using multilevel modeling (e.g., Heck, Thomas, \& Tabata, 2010). Time 0 was defined as the date of the first assessment at two weeks (baseline) and the time variable was scored in weeks from the baseline to six months. The intercept refers to sleep-wake behaviors (sleep hours, awake hours, awakenings, latency to sleep, and longest sleep period - during the 24-h period, day, and night) at the baseline and the slope for time the extent to which sleep-wake behaviors change each week. Scores for all sleep-wake variables (during the 24-h period, day, and night) were examined at each assessment wave. Empty models were tested and individual stability was calculated dividing the intercept variance by the total variance. Data consisted of 282 observations ( 94 participants by 3 time points). The effect size $r$ (Rosenthal, Rosnow, \& Rubin, 2000) was estimated for all significant effects and interpreted according to Cohen's guidelines (1988). In order to analyze associations between infant sleep-wake behaviors during the 24-h period, day and night between two weeks and six months, Pearson correlations were performed.

Statistical analyses were performed using the software SPSS version 23.0 (SPSS Inc., USA).

\section{Results}

\subsection{Infant sleep-wake behaviors at two weeks, three months, and six months}

Table 2 shows the means, standard deviations and range for sleep hours, awake hours, awakenings, latency to sleep, and longest sleep period (24-h period, day, and night) at two weeks, three and six months. Table 3 shows associations between infant sleep-wake behaviors during the day and the night at two weeks, three, and six months.

Two-week-old infants sleep a mean of $13.27 \mathrm{~h}$ during the 24-h period, $6.35 \mathrm{~h}$ during the day, and $6.91 \mathrm{~h}$ during the night. They spend a mean of $8.69 \mathrm{~h}$ awake during the 24 -h period, $4.62 \mathrm{~h}$ during the day and $4.07 \mathrm{~h}$ during the night. They have averaged $0.35 \mathrm{~h}$ of latency to sleep during the 24 -h period, $0.36 \mathrm{~h}$ during the day and $0.38 \mathrm{~h}$ during the night. At this age, infants awake a mean of 6.05 times during the 24-h period, 3.16 times during the day and 2.95 times during the night. They have averaged $3.20 \mathrm{~h}$ of longest sleep period during the 24 -h period, $2.57 \mathrm{~h}$ during the day and $3.04 \mathrm{~h}$ during the night. 
Table 2

Means, standard deviations, and range for sleep hours, awake hours, awakenings, longest sleep period, and latency to sleep at two weeks, three months, and six months.

\begin{tabular}{|c|c|c|c|c|c|c|}
\hline \multirow[b]{2}{*}{ Variable } & \multicolumn{2}{|l|}{2 weeks } & \multicolumn{2}{|l|}{3 months } & \multicolumn{2}{|l|}{6 months } \\
\hline & $\mathrm{M}(\mathrm{SD})$ & Range & $\mathrm{M}(\mathrm{SD})$ & Range & $\mathrm{M}(\mathrm{SD})$ & Range \\
\hline Sleep 24-h & $13.27(2.38)$ & $4.50-18.50$ & $12.95(2.40)$ & $1.50-17.50$ & $12.21(2.18)$ & $3.50-15.50$ \\
\hline Sleep day & 6.35 (1.39) & $2.50-9.00$ & $4.95(1.55)$ & $0.00-8.50$ & $4.02(1.30)$ & $0.00-7.00$ \\
\hline Sleep night & $6.91(1.40)$ & $1.50-9.50$ & $8.01(1.48)$ & $1.50-11.50$ & $8.20(1.78)$ & $0.00-10-50$ \\
\hline Awake 24-h & $8.69(2.09)$ & $4.00-16.00$ & $9.19(2.03)$ & $4.50-14.00$ & $9.98(1.62)$ & $6.50-16.50$ \\
\hline Awake day & $4.62(1.36)$ & $2.00-9.50$ & $6.06(1.62)$ & $2.50-10.00$ & 7.15 (1.39) & $4.00-12.00$ \\
\hline Awake night & $4.07(1.28)$ & $1.00-7.50$ & $3.13(1.16)$ & $0.50-6.50$ & $2.83(1.07)$ & $1.00-5.00$ \\
\hline Awakenings 24-h & $6.05(1.25)$ & $3.00-9.00$ & $5.54(1.60)$ & $2.00-11.00$ & $5.19(1.39)$ & $1.00-9.00$ \\
\hline Awakenings day & $3.16(0.86)$ & $1.00-6.00$ & $3.30(1.06)$ & $0.00-6.00$ & $3.10(0.89)$ & $0.00-5.00$ \\
\hline Awakenings night & $2.95(0.81)$ & $1.00-5.00$ & $2.24(1.07)$ & $0.00-6.00$ & $2.11(1.05)$ & $0.00-4.00$ \\
\hline Latency to sleep 24-h & $0.35(0.34)$ & $0.00-1.70$ & $0.38(0.62)$ & $0.00-5.50$ & $0.39(0.47)$ & $0.00-3.33$ \\
\hline Latency to sleep day & $0.36(0.44)$ & $0.00-2.75$ & $0.34(0.50)$ & $0.00-4.00$ & $0.29(0.29)$ & $0.00-1.33$ \\
\hline Latency to sleep night & $0.38(0.41)$ & $0.00-2.00$ & $0.46(0.70)$ & $0.00-4.50$ & $0.56(1.20)$ & $0.00-9.00$ \\
\hline Longest sleep period 24-h & $3.20(1.12)$ & $1.50-7.00$ & $5.24(2.11)$ & $1.00-11.00$ & $5.59(2.55)$ & $1.00-10.50$ \\
\hline Longest sleep period day & $2.57(0.87)$ & $1.00-6.00$ & $2.09(0.70)$ & $0.00-3.50$ & $1.84(0.72)$ & $0.00-4.00$ \\
\hline Longest sleep period night & $3.04(1.12)$ & $1.00-7.00$ & $5.24(2.11)$ & $1.00-11.00$ & $5.56(2.60)$ & $0.00-10.50$ \\
\hline
\end{tabular}

Notes. $M=$ Mean; $S D=$ Standard Deviation.

Table 3

Associations between infant sleep-awake behaviors during the day and the night at two weeks, three months, and six months.

\begin{tabular}{|c|c|c|c|c|c|c|}
\hline & \multirow[b]{2}{*}{2 weeks } & \multicolumn{5}{|l|}{ Day } \\
\hline & & Sleep & Awake & Awakenings & Latency to sleep & Longest sleep period \\
\hline \multirow[t]{17}{*}{ Night } & Sleep & $0.456^{* * *}$ & -0.073 & 0.177 & $-0.474^{* * *}$ & $0.406^{* * *}$ \\
\hline & Awake & -0.163 & $0.245^{*}$ & $-0.299^{* *}$ & -0.006 & -.102 \\
\hline & Awakenings & 0.022 & -0.057 & 0.090 & 0.021 & $-0.431^{* * *}$ \\
\hline & Latency to sleep & $-0.361^{* * *}$ & -0.127 & 0.111 & $0.516^{* * *}$ & $-0.288^{* *}$ \\
\hline & \multirow[t]{2}{*}{ Longest sleep period } & $0.211^{*}$ & 0.001 & -0.029 & $-0.212^{*}$ & $0.472^{* * *}$ \\
\hline & & Sleep & Awake & Awakenings & Latency to sleep & Longest sleep period \\
\hline & Sleep & $0.257^{*}$ & -0.024 & $0.221^{*}$ & $-0.491^{* * *}$ & $0.259^{*}$ \\
\hline & Awake & 0.037 & 0.039 & -0.085 & -0.017 & -0.064 \\
\hline & Awakenings & -0.012 & -0.113 & 0.125 & 0.123 & -0.164 \\
\hline & Latency to sleep & $-0.318^{* *}$ & 0.021 & -0.176 & $0.522^{* * *}$ & $-0.219^{*}$ \\
\hline & Longest sleep period & 0.054 & 0.059 & -0.108 & $-0.215^{*}$ & 0.187 \\
\hline & 6 months & Sleep & Awake & Awakenings & Latency to sleep & Longest sleep period \\
\hline & Sleep & -0.025 & 0.158 & $0.228^{*}$ & $-0.297^{* *}$ & -0.130 \\
\hline & Awake & $0.219^{*}$ & -0.153 & -0.180 & -0.021 & $0.217^{*}$ \\
\hline & Awakenings & 0.074 & 0.133 & 0.046 & 0.078 & 0.008 \\
\hline & Latency to sleep & -0.133 & 0.046 & -0.162 & 0.182 & 0.031 \\
\hline & Longest sleep period & 0.066 & 0.089 & -0.009 & -0.057 & -0.055 \\
\hline
\end{tabular}

${ }^{*} p<0.05 ;{ }^{* *} p<0.01 ;{ }^{* * *} p<0.001$

At two weeks significant correlations between the day and the night were found on sleep hours, $r=0.456, p<0.001$, awake hours, $r=0.245, p=0.017$, latency to sleep, $r=0.516, p<0.001$, and longest sleep period, $r=0.472, p<0.001$. Non-significant correlations between the day and the night were found on awakenings, $r=0.090, p=0.389$ (Table 3 ).

Three-month-old infants sleep a mean of $12.95 \mathrm{~h}$ during the 24 - $\mathrm{h}$ period, $4.95 \mathrm{~h}$ during the day and $8.01 \mathrm{~h}$ during the night. They spend a mean of $9.19 \mathrm{~h}$ awake during the 24 -h period, $6.06 \mathrm{~h}$ during the day and $3.13 \mathrm{~h}$ during the night. They have averaged $0.38 \mathrm{~h}$ of latency to sleep during the 24 -h period, $0.34 \mathrm{~h}$ during the day and $0.46 \mathrm{~h}$ during the night. At this age, infants awake a mean of 5.54 times during the 24-h period, 3.30 times during the day and 2.24 times during the night. They have averaged $5.24 \mathrm{~h}$ of longest sleep period during the 24 -h period, $2.09 \mathrm{~h}$ during the day and $5.24 \mathrm{~h}$ during the night.

At three months significant correlations between the day and the night were found on sleep hours, $r=0.257, p=0.012$, and latency to sleep, $r=0.522, p<0.001$. Non-significant correlations between the day and the night were found on awake hours, $r=0.039, p=0.712$, awakenings, $r=0.125, p=0.231$, and longest sleep period, $r=0.187, p=0.072$.

Six-month-old infants sleep a mean of $12.21 \mathrm{~h}$ during the 24 -h period, $4.02 \mathrm{~h}$ during the day and $8.20 \mathrm{~h}$ during the night. They spend a mean of $9.98 \mathrm{~h}$ awake during the 24 -h period, $7.15 \mathrm{~h}$ during the day and $2.83 \mathrm{~h}$ during the night. They have averaged $0.39 \mathrm{~h}$ of latency to sleep during the 24 -h period, $0.29 \mathrm{~h}$ during the day and $0.56 \mathrm{~h}$ during the night. At this age, infants awake a mean of 5.19 times during the 24 -h period, 3.10 times during the day and 2.11 times during the night. They have averaged $5.59 \mathrm{~h}$ of longest sleep period during the 24 -h period, $1.84 \mathrm{~h}$ during the day and $5.56 \mathrm{~h}$ during the night. 
Table 4

Associations between infant sleep-wake behaviors at two weeks and six months and the role of individual change and stability in infant sleep-wake behaviors from two weeks to six months.

\begin{tabular}{|c|c|c|c|}
\hline Variable & $\begin{array}{l}\text { Associations between infant sleep-wake behaviors } \\
r\end{array}$ & $\begin{array}{l}\text { Individual stability } \\
r\end{array}$ & $\begin{array}{l}\text { Individual change } \\
r\end{array}$ \\
\hline Sleep 24-h & $0.210^{*}$ & $0.91^{* * *}$ & $0.09^{* * *}$ \\
\hline Sleep day & 0.006 & $0.92^{* * *}$ & $0.08^{* * *}$ \\
\hline Sleep night & $0.228^{*}$ & $0.87^{* * *}$ & $0.13^{* * *}$ \\
\hline Awake 24-h & 0.194 & $0.91^{* * *}$ & $0.09^{* * *}$ \\
\hline Awake day & 0.129 & $0.91^{* * *}$ & $0.09^{* * *}$ \\
\hline Awake night & $0.204^{*}$ & $0.95^{* * *}$ & $0.05^{* * *}$ \\
\hline Awakenings 24-h & 0.168 & $0.94^{* * *}$ & $0.06^{* * *}$ \\
\hline Awakenings day & 0.064 & $0.98^{* * *}$ & 0.02 \\
\hline Awakenings night & 0.045 & $0.91^{* * *}$ & $0.09^{* * *}$ \\
\hline Latency to sleep 24-h & $0.288^{* *}$ & $0.95^{* * *}$ & 0.05 \\
\hline Latency to sleep day & $0.499^{* * *}$ & $0.98^{* * *}$ & 0.02 \\
\hline Latency to sleep night & 0.097 & $0.95^{* * *}$ & 0.05 \\
\hline Longest sleep period $24-\mathrm{h}$ & 0.122 & $0.93^{* * *}$ & $0.07^{* * *}$ \\
\hline Longest sleep period day & -0.089 & $0.90^{* * *}$ & $0.10^{* * *}$ \\
\hline Longest sleep period night & 0.150 & $0.93^{* * *}$ & $0.07^{* * *}$ \\
\hline
\end{tabular}

${ }^{*} p<0.05 ;{ }^{* *} p<0.01 ;{ }^{* * *} p<0.001$

At six months, non-significant correlations between the day and the night were found on sleep hours, $r=-0.025, p=0.814$, awake hours, $r=-0.153, p=0.142$, awakenings, $r=0.046, p=0.658$, latency to sleep, $r=0.182, p=0.078$, and longest sleep period, $r=-0.055, p=0.597$.

\subsection{Developmental changes on infant sleep-wake behaviors from two weeks to six months}

From two weeks to six months, (1) sleep hours during the 24-h period decreased, in average, $0.04 \mathrm{~h}$ per week, $b=-0.04$, $S E=0.01,95 \% C I=[-0.07,-0.02], p=0.002$, effect size $r=0.19$, sleep hours during the day decreased, in average, $0.10 \mathrm{~h}$ per week, $b=-0.10, S E=0.01,95 \% C I=[-0.11,-0.08], p<0.001$, effect size $r=0.56$, while sleep hours during the night increased, in average, $0.05 \mathrm{~h}$ per week, $b=0.05, S E=0.01,95 \% C I=[0.03,0.07], p<0.001$, effect size $r=0.33$; (2) awake hours during the 24-h period increased, in average, $0.05 \mathrm{~h}$ per week, $b=0.05, S E=0.01,95 \% C I=[0.03,0.08], p<0.001$, effect size $r=0.27$, awake hours during the day increased, in average, $0.10 \mathrm{~h}$ per week, $b=0.10, S E=0.01,95 \% C I=[0.09,0.12], p<0.001$, effect size $r=0.59$, while awake hours during the night decreased, in average, $0.05 \mathrm{~h}$ per week, $b=-0.05, S E=0.01,95 \% C I=[-0.06,-0.04], p<0.001$, effect size $r=0.38$; (3) awakenings during the 24-h period decreased, in average, 0.04 times per week, $b=-0.04, S E=0.01$, $95 \% C I=[-0.05,-0.02], p<0.001$, effect size $r=0.25$, no changes were found on awakenings during the day, and awakenings during the night decreased, in average, 0.33 times per week, $b=-0.33, S E=0.01,95 \% C I=[-0.05,-0.02], p<0.001$, effect size $r=0.34$; and (4) longest sleep period hours during the 24-h period increased, in average, $0.09 \mathrm{~h}$ per week, $b=0.09, S E=0.01$, $95 \% C I=[0.07,0.12], p<0.001$, effect size $r=0.47$, longest sleep period hours during the day decreased, in average, $0.03 \mathrm{~h}$ per week, $b=-0.03, S E=0.01,95 \% C I=[-0.04,-0.02], p<0.001$, effect size $r=0.37$, while longest sleep period hours during the night increased, in average, $0.10 \mathrm{~h}$ per week, $b=0.10, S E=0.13,95 \% C I=[0.07,-0.13], p<0.001$, effect size $r=0.48$. No developmental changes were found on latency to sleep hours during 24-h period, day and night. Intercepts and random effects (intercept + time; residuals) were statistically significant (all p's $<0.001$ ) in all the models.

\subsection{Individual change and stability on infant sleep-wake behaviors from two weeks to six months}

Table 4 shows associations between infant sleep-wake behaviors at two weeks and six months, and individual change and individual stability on infant sleep-wake behaviors from two weeks to six months.

Significant correlations between two weeks and six months were found on sleep hours during the 24-h period, $r=0.210$, $p=0.042$, and during the night, $r=0.228, p=0.027$, awake hours during the night, $r=0.204, p=0.049$, latency to sleep during the 24-h period, $r=0.288, p=0.005$, and during the day, $r=0.499, p<0.001$. Non-significant correlations between two weeks and six months were found for the remaining infant sleep-wake behaviors (see Table 4).

The proportion of variance explained by individual change from two weeks to six months was between 0.02 for awakenings and latency to sleep during the day and 0.13 for sleep during the night. Non-significant variance explained was found for awakenings during the day, and latency to sleep during the 24-h period, the day and the night (see Table 4). Empty models for infant sleep-wake behaviors indicated that the proportion of variance explained by individual stability from two weeks to six months was between 0.87 , for sleep during the night and 0.98 , for awakenings and latency to sleep during the day. Significant variance explained was found for all the infant sleep-wake behaviors (see Table 4). 


\section{Discussion}

\subsection{Infant sleep-wake behaviors at two weeks, three months, and six months}

Two-week-old infants sleep a mean of $13.27 \mathrm{~h}$ during the 24 -h period, $6.35 \mathrm{~h}$ during the day, and $6.91 \mathrm{~h}$ during the night. Results for sleep hours at two weeks are content with the literature for sleep hours during the 24-h period (e.g., Iglowstein et al., 2003), the day (e.g., Montgomery-Downs \& Gozal, 2006), and the night at one month (e.g., Montgomery-Downs \& Gozal, 2006). They spend a mean of $8.69 \mathrm{~h}$ awake during the 24 -h period, $4.62 \mathrm{~h}$ during the day and $4.07 \mathrm{~h}$ during the night. To our knowledge there are no studies on awake hours during the 24-h period and during the day for this age range, so cross-study comparisons cannot be performed. Awake hours during the night at two weeks are slightly higher than the average found in previous studies for awake hours at one month (e.g., Tikotzky \& Sadeh, 2009). At this age, infants awake a mean of 6.05 times during the 24-h period, 3.16 times during the day and 2.95 times during the night. Number of total awakenings at two weeks is slightly higher than in a previous study at one month (Montgomery-Downs \& Gozal, 2006). However, number of awakenings is in the range of the reference values found in the literature for awakenings during the day (e.g., Matthey, 2001; Montgomery-Downs \& Gozal, 2006) and during the night at one month (e.g., Burnham et al., 2002; Goodlin-Jones et al., 2001; Montgomery-Downs \& Gozal, 2006).They have averaged $0.35 \mathrm{~h}$ of latency to sleep during the 24-h period, 0.36 $\mathrm{h}$ during the day and $0.38 \mathrm{~h}$ during the night. Latency to sleep at two weeks is consistent with the average values found in previous studies either during the day either during the night at one month (Matthey, 2001; Tikotzky \& Sadeh, 2009). They have averaged $3.20 \mathrm{~h}$ of longest sleep period during the 24 -h period, $2.57 \mathrm{~h}$ during the day and $3.04 \mathrm{~h}$ during the night. To our knowledge there are no studies on the longest sleep period during the 24-h period and during the day, so cross-study comparisons cannot be performed. The longest sleep period during the night is consistent with the average values presented in earlier studies (Anders \& Keener, 1985; Burnham et al., 2002; Goodlin-Jones et al., 1997).

Three-month-old infants sleep a mean of $12.95 \mathrm{~h}$ during the 24 -h period, $4.95 \mathrm{~h}$ during the day and $8.01 \mathrm{~h}$ during the night. Results for sleep hours during the total 24-h period at three months are consistent with the average values and ranges presented in earlier studies (e.g., Bruni et al., 2014; Harrison, 2004; Iglowstein et al., 2003). Although in content with the range presented in literature (Iglowstein et al., 2003), sleep hours during the day are slightly higher and sleep hours during the night are slightly lower than the averages presented in earlier studies (e.g., Bruni et al., 2014; Tikotzky et al., 2015). At this age, infants awake a mean of 5.54 times during the 24-h period, 3.30 times during the day and 2.24 times during the night. At three months, number of awakenings is in the range of the reference values found in the literature for awakenings during the day (e.g., Bruni et al., 2014) and during the night (e.g., Burnham et al., 2002; Goodlin-Jones et al., 2001). They spend a mean of $9.19 \mathrm{~h}$ awake during the 24 -h period, $6.06 \mathrm{~h}$ during the day and $3.13 \mathrm{~h}$ during the night. They have averaged $0.38 \mathrm{~h}$ of latency to sleep during the 24 -h period, $0.34 \mathrm{~h}$ during the day and $0.46 \mathrm{~h}$ during the night. To our knowledge there are no studies on awake hours and latency to sleep at three months, so cross-study comparisons cannot be made. They have averaged $5.24 \mathrm{~h}$ of longest sleep period during the 24 -h period, $2.09 \mathrm{~h}$ during the day and $5.24 \mathrm{~h}$ during the night. Similarly, the longest sleep period during the night at three months is consistent with the average values presented in earlier studies (Anders \& Keener, 1985; Burnham et al., 2002; Goodlin-Jones et al., 2001).

Six-month-old infants sleep a mean of $12.21 \mathrm{~h}$ during the 24-h period, $4.02 \mathrm{~h}$ during the day and $8.20 \mathrm{~h}$ during the night. Results for sleep hours during the total 24-h period are content with literature on total sleep hours at this age (e.g., Blair et al., 2012; Iglowstein et al., 2003; Montgomery-Downs \& Gozal, 2006). However, although in content with the range presented in literature (Iglowstein et al., 2003; Montgomery-Downs \& Gozal, 2006), sleep hours during the day are slightly higher and sleep hours during the night are slightly lower than the averages presented in earlier studies at this age (e.g., Bruni et al., 2014; Tikotzky et al., 2010, 2015). They spend a mean of $9.98 \mathrm{~h}$ awake during the 24-h period, $7.15 \mathrm{~h}$ during the day and $2.83 \mathrm{~h}$ during the night. Although no cross-study comparisons can be performed on awake hours during the 24-h period and during the day for this age range, awake hours during the night at six months are higher than the average found in previous studies (e.g., Tikotzky \& Sadeh, 2009). At this age, infants awake a mean of 5.19 times during the 24-h period, 3.10 times during the day and 2.11 times during the night. Number of total awakenings and awakenings during the day are slightly higher than in earlier studies (Bruni et al., 2014; Matthey, 2001; Montgomery-Downs \& Gozal, 2006). Number of awakenings during the night is in the range of the reference values found in the literature (e.g., Burnham et al., 2002; Goodlin-Jones et al., 2001; Montgomery-Downs \& Gozal, 2006; Tikotzky et al., 2015). They have averaged 0.39 h of latency to sleep during the 24-h period, $0.29 \mathrm{~h}$ during the day and $0.56 \mathrm{~h}$ during the night. Results for latency to sleep during the day and during the night at six months are consistent with the average values found in earlier studies (Matthey, 2001; Tikotzky \& Sadeh, 2009). They have averaged $5.59 \mathrm{~h}$ of longest sleep period during the 24-h period, $1.84 \mathrm{~h}$ during the day and $5.56 \mathrm{~h}$ during the night. Longest sleep period during the night at six months is also consistent with the average values presented in earlier studies (Anders \& Keener, 1985; Burnham et al., 2002; Goodlin-Jones et al., 2001).

Significant associations were found at two weeks between day and night sleep hours, awake hours, latency to sleep, and longest sleep period. These results showed that infant sleep hours, awake hours, latency to sleep, and longest sleep period at two weeks were positively correlated between the day and the night, meaning that the more time an infant spend sleeping, awake, in latency to sleep and with longer sleep period during the day more time spend sleeping, awake, in latency to sleep and with longer sleep period during the night. However, previous significant associations at two weeks on awake hours and longest sleep period between the day and the night were not significant at three months. Additionally, all previous significant associations between day and night same sleep-wake behaviors at two weeks and three months were not significant at six 
months. These results are in line with infant sleep literature suggesting that at three months infants begin to discriminate between day and night and that at six months infants achieve distinct patterns of sleep-wake behaviors during the day and the night (e.g., Meltzer \& Mindell, 2006; Sadeh, 2000).

\subsection{Developmental changes on infant sleep-wake behaviors from two weeks to six months}

Significant developmental changes were found on infant sleep-wake behaviors during the first six months of life, consistent with previous studies, but few used growth curve models (e.g., Bruni et al., 2014; Burnham et al., 2002).

From two weeks to six months, infants presented a decrease on sleep hours during the 24-h period and during the day, while an increase on sleep hours during the night, in accordance with previous research (e.g., Sadeh et al., 2009; Teng et al., 2012; Tikotzky \& Sadeh, 2009; Matthey, 2001). Also in content with previous research, from two weeks to six months the time that infants spent awake presented an increase during the 24-h period and during the day, while a decrease during the night (e.g., Sadeh et al., 2009; Teng et al., 2012; Tikotzky \& Sadeh, 2009). Results showed a decrease on the number of sleep periods/awakenings during the 24-h period and the night from two weeks to six months, in accordance with previous studies (e.g., Sadeh et al., 2009; Montgomery-Downs \& Gozal, 2006; Teng et al., 2012; Tikotzky \& Sadeh, 2009). However, contrary to what would be supposed according to previous studies, no developmental changes were found on the number of sleep periods/awakenings during the day (e.g., Matthey, 2001; Sadeh et al., 2009; Teng et al., 2012) and on the latency to sleep during the 24-h period, day and night (Matthey, 2001; Tikotzky \& Sadeh, 2009), from two weeks to six months. Results also showed that infant's longest sleep period increases during the 24-h period, decreasing during the day, while increasing during the night from two weeks to six months, in accordance with literature (Burnham et al., 2002; Goodlin-Jones et al., 1997; Teng et al., 2012).

\subsection{Individual change and stability on infant sleep-wake behaviors from two weeks to six months}

Despite both individual change and individual stability were significant, individual stability was found to explain more variance on infant sleep-wake behaviors during the 24 -h period, day, and night, from two weeks to six months. These results suggested that independently of the observed individual change on infant sleep-wake behaviors from two weeks to six months, individual differences (indicated by the high individual stability from two weeks to six months) remain over time. Infants who spend more time sleeping, awaked, with more awakenings, with more prolonged latency to sleep, and a longest sleep period at two weeks are those who spend more time sleeping, awaked, with more awakenings, with more prolonged latency to sleep, and a longest sleep period at six months.

These results are congruent with previous studies that showed that infant sleep-wake behaviors during the first months of life are significantly explained by individual differences (e.g., Bruni et al., 2014; Burnham et al., 2002), and that individual differences and individual stability explain infant sleep-wake behaviors values and trajectories over the first six months (Scher et al., 2004; St James-Roberts \& Plewis, 1996).

\subsection{Limitations}

Reported reference values and developmental changes in the present study for infant sleep-wake behaviors from two weeks to six months are quite similar to those proposed in previous studies. However, few differences are presented, which, despite cultural differences, may be related to differences in procedures and measures, and sample characteristics.

Regarding procedures and measures, while this study used the Infant Sleep Chronogram to obtain infant sleep-wake behaviors, other studies used questionnaires (e.g., Mindell et al., 2010; Sadeh et al., 2009) or actigraphic measures (e.g., Tikotzky et al., 2010). Good reliability has been stated between maternal report and more other sleep measures, such as actigraphy (e.g., Müller, Hemmi, Wilhelm, Barr, \& Schneider, 2011; Sadeh, 2004; Werner, Molinari, Guyer, \& Jenni, 2008). The Infant Sleep Chronogram assessed infant sleep-wake behaviors through mothers' reports, which might be biased by their perceptions. However, this measure showed good internal consistency and significant correlations were found between the day and night sleep-wake behaviors, which suggest accuracy on maternal reports both during the day and the night. Some differences in the definitions of daytime and nighttime periods may also contribute to differences in reference values and reported developmental changes for infant sleep-wake behaviors at two weeks, three and six months. In the present study "daytime" was defined from 8 a.m. to 8 p.m. and "nighttime" from 8 p.m. to 8 a.m., while some studies considered the daytime period from 7 a.m. to 7 p.m. and the nighttime period from 7 p.m. to 7 a.m. (e.g., Mindell et al., 2010; Sadeh et al., 2009), other studies considered bedtime from 5 p.m. and wake time from 9 a.m. (e.g., Iglowstein et al., 2003), and other studies not indicating the definition of daytime and nighttime periods (e.g., Blair et al., 2012; Bruni et al., 2014).

Sample characteristics also varied across studies, with our sample having a higher rate of exclusive breastfeeding (e.g., Bruni et al., 2014; Quillin, 1997) and bed sharing (at least once a week) (e.g, Bruni et al., 2014; Montgomery-Downs \& Gozal, 2006) than previous studies. And including only first-born and healthy infants, while other samples were not limited to first-born infants (e.g., Bruni et al., 2014; Quillin, 1997; Montgomery-Downs \& Gozal, 2006). Exclusive breastfeeding (e.g., Engler, Hadash, Shehadeh, \& Pillar, 2012; Nevarez, Rifas-Shiman, Kleinman, Gillman, \& Taveras, 2010; Quillin, 1997) and sleep arrangements (e.g., Volkovich, Zion, Karny, Meiri, \& Tikotzky, 2015) are two key variables associated with infant sleepwake behavior in previous research. Nonetheless, birth order did not appear to affect sleep-wake behaviors in at least one 
earlier study (e.g., So, Adamson, \& Horne, 2007). Infant age also differed across studies, with some comparing sleep-wake behaviors at specific ages, as it was performed in this study (Blair et al., 2012; Bruni et al., 2014; Montgomery-Downs \& Gozal, 2006), while others grouped infants across age ranges (e.g., Mindell et al., 2010; Sadeh et al., 2009).

This study contributed to infant sleep research and practice by indicating reference values for several relevant infant sleep-wake behaviors at two weeks, three and six months, and showing associations between same infant sleep-wake behaviors during the day and the night, at two weeks but not at six months. Showing several developmental changes on infant sleep-wake behavior from two weeks to six months through curve growth analyzes and suggesting that, despite of developmental changes and individual change, individual stability explain a significant amount of the variance on infant sleep-wake behaviors from two weeks to six months is also a contribution of the present study. To our knowledge no study analyzed individual change and stability on infant sleep-wake behavior during the first six months. In that sense, our data extended the current knowledge on infant sleep-wake behavior, by analyzing the role of individual change and stability on infant sleep-wake behaviors over the first six months.

\section{Acknowledgments}

This research was supported by FEDER Funds through the Programa Operacional Factores de Competitividade - COMPETE and by National Funds through FCT - Fundação para a Ciência e a Tecnologia under the project: PTDC/SAU/SAP/116738/2010 and SFRH/BSAB/14445/2014 grant.

This study was conducted at Psychology Research Centre (UID/PSI/01662/2013), University of Minho, and supported by the Portuguese Foundation for Science and Technology and the Portuguese Ministry of Education and Science through national funds and co-financed by FEDER through COMPETE2020 under the PT2020 Partnership Agreement (POCI-01-0145FEDER-007653).

\section{References}

Anders, T. F., \& Keener, M. (1985). Developmental course of nighttime sleep-wake patterns in full-term and premature infants during the first year of life. I. Sleep: 8., (3), 173-192. Retrieved from. http://psycnet.apa.org/psycinfo/1989-29022-001

Anders, T. F., Halpern, L. F., \& Hua, J. (1992). Sleeping through the night: a developmental perspective. Pediatrics: 90., (4), 554-560. Retrieved from. http://pediatrics.aappublications.org/content/90/4/554.short

Blair, P. S., Humphreys, J. S., Gringras, P., Taheri, S., Scott, N., Emond, A., .. . \& Fleming, P. J. (2012). Childhood sleep duration and associated demographic characteristics in an English cohort. Sleep: 35., (3), 353-360. http://dx.doi.org/10.5665/sleep.1694

Bruni, O., Baumgartner, E., Sette, S., Ancona, M., Caso, G., Di Cosimo, M. E., .. . \& Ferri, R. (2014). Longitudinal study of sleep behavior in normal infants during the first year of life. Journal of Clinical Sleep Medicine: 10., (10), 1119-1127. http://dx.doi.org/10.5664/jcsm.4114

Burnham, M. M., Goodlin-Jones, B. L., Gaylor, E. E., \& Anders, T. F. (2002). Nighttime sleep-wake patterns and self-soothing from birth to one year of age: a longitudinal intervention study. Journal of Child Psychology and Psychiatry: 43., (6), 713-725. http://dx.doi.org/10.1111/1469-7610.00076

Byars, K. C., Yolton, K., Rausch, J., Lanphear, B., \& Beebe, D. W. (2012). Prevalence, patterns, and persistence of sleep problems in the first 3 years of life. Pediatrics: 129., (2), e276-e284. http://dx.doi.org/10.1542/peds.2011-0372

Cohen, J. (1988). Statistical power analysis for the behavioral sciences (2nd ed.)). New Jersey: Lawrence Erlbaum.

Engler, A. C., Hadash, A., Shehadeh, N., \& Pillar, G. (2012). Breastfeeding may improve nocturnal sleep and reduce infantile colic: potential role of breast milk melatonin. European Journal of Pediatrics: 171., (4), 729-732. http://dx.doi.org/10.1007/s00431-011-1659-3

Freudigman, K. A., \& Thoman, E. B. (1993). Infant sleep during the first postnatal day: an opportunity for assessment of vulnerability. Pediatrics: 92., (3), 373-379.

Galland, B. C., Taylor, B. J., Elder, D. E., \& Herbison, P. (2012). Normal sleep patterns in infants and children: a systematic review of observational studies. Sleep Medicine Reviews: 16., (3), 213-222. http://dx.doi.org/10.1016/j.smrv.2011.06.00

Goodlin-Jones, B. L., Eiben, L. A., \& Anders, T. F. (1997). Maternal well-being and sleep-wake behaviors in infants: an intervention using maternal odor. Infant Mental Health Journal: 18., (4), 378-393. http://dx.doi.org/10.1111/j.1365-2869.2004.0043510.1002/(SICI)1097-0355(199724)18<378:AID-IMHJ5>3.0.CO;2-H

Goodlin-Jones, B. L., Burnham, M. M., Gaylor, E. E., \& Anders, T. F. (2001). Night waking, sleep-wake organization, and self-soothing in the first year of life. Journal of Developmental \& Behavioral Pediatrics: 22., (4), 226-233. http://dx.doi.org/10.1097/00004703-200108000-00003

Harrison, Y. (2004). The relationship between daytime exposure to light and night-time sleep in 6-12-week-old infants. Journal of Sleep Research: 13., (4), 345-352. http://dx.doi.org/10.1111/j.1365-2869.2004.00435.x

Heck, R. H., Thomas, S. L., \& Tabata, L. N. (2010). Multilevel and longitudinal modeling with IBM SPSS. New York: Routledge.

Henderson, J. M., France, K. G., Owens, J. L., \& Blampied, N. M. (2010). Sleeping through the night: the consolidation of self-regulated sleep across the first year of life. Pediatrics: 126., (5), e1081-e1087. http://dx.doi.org/10.1542/peds.2010-0976

Henderson, J. M., France, K. G., \& Blampied, N. M. (2011). The consolidation of infants' nocturnal sleep across the first year of life. Sleep Medicine Reviews: 15., (4), 211-220. http://dx.doi.org/10.1016/j.smrv.2010.08.003

Iglowstein, I., Jenni, O. G., Molinari, L., \& Largo, R. H. (2003). Sleep duration from infancy to adolescence: reference values and generational trends. Pediatrics: 111., (2), 302-307. http://dx.doi.org/10.1542/peds.111.2.302

Ingersoll, E. W., \& Thoman, E. B. (1999). Sleep/wake states of preterm infants: stability, developmental change, diurnal variation, and relation with caregiving activity. Child Development: 70., (1), 1-10.

Müller, S., Hemmi, M. H., Wilhelm, F. H., Barr, R. G., \& Schneider, S. (2011). Parental report of infant sleep behavior by electronic versus paper-and-pencil diaries, and their relationship to actigraphic sleep measurement. Journal of Sleep Research: 20., 598-605. http://dx.doi.org/10.1111/j.1365-2869.2011.00926.x

Magee, C. A., Gordon, R., \& Caputi, P. (2014). Distinct developmental trends in sleep duration during early childhood. Pediatrics: 133., (6), e1561-e1567. http://dx.doi.org/10.1542/peds.2013-3806

Matthey, S. (2001). The sleep and settle questionnaire for parents of infants: psychometric properties. Journal of Paediatrics and Child Health: 37., (5), 470-475. http://dx.doi.org/10.1046/j.1440-1754.2001.00703.x

Meltzer, L. J., \& Mindell, J. A. (2006). Sleep and sleep disorders in children and adolescents. Psychiatric Clinics of North America: $29 ., 1059-1076$. http://dx.doi.org/10.1016/j.psc.2006.08.004

Mindell, J. A., Meltzer, L. J., Carskadon, M. A., \& Chervin, R. D. (2009). Developmental aspects of sleep hygiene: findings from the 2004 national sleep foundation sleep in america poll. Sleep Medicine: 10., (7), 771-779. http://dx.doi.org/10.1016/j.sleep.2008.07.016 
Mindell, J. A., Sadeh, A., Wiegand, B., How, T. H., \& Goh, D. Y. T. (2010). Cross-cultural differences in infant and toddler sleep. Sleep Medicine: 11., 274-280. http://dx.doi.org/10.1016/j.sleep.2009.04.012

Montgomery-Downs, H. E., \& Gozal, D. (2006). Sleep habits and risk factors for sleep-disordered breathing in infants and young toddlers in Louisville, Kentucky. Sleep Medicine: 7., 211-219. http://dx.doi.org/10.1016/j.sleep.2005.11.003

Nevarez, M. D., Rifas-Shiman, S. L., Kleinman, K. P., Gillman, M. W., \& Taveras, E. M. (2010). Associations of early life risk factors with infant sleep duration. Academic Pediatrics: 10., (3), 187-193. http://dx.doi.org/10.1016/j.acap.2010.01.007

Parmalee, A. J., Wenner, W. H., \& Schulz, H. R. (1964). Infant sleep patterns: from birth to 16 weeks of age. The Journal of Pediatrics: 65., (4), 576-582.

Quillin, S. I. (1997). Infant and mother sleep patterns during 4th postpartum week. Issues in Comprehensive Pediatric Nursing: 20., (2), 115-123. http://dx.doi.org/10.3109/01460869709026882

Rosenthal, R., Rosnow, R. L., \& Rubin, D. B. (2000). Contrasts and effect sizes in behavioral research: a correlational approach. Cambridge: Cambridge: University Press.

Sadeh, A., Mindell, J. A., Luedtke, K., \& Wiegand, B. (2009). Sleep and sleep ecology in the first 3 years: a web-based study. Journal of Sleep Research: 18., (1), 60-73. http://dx.doi.org/10.1111/j.1365-2869.2008.00699.x

Sadeh, A. (2000). Maturation of normal sleep patterns from childhood through adolescence. In G. M. Loughlin, J. L. Carroll, \& C. L. Marcus (Eds.), Sleep and breathing in children: a developmental approach. New York: Marcel Dekker.

Sadeh, A. (2004). A brief screening questionnaire for infant sleep problems: validation and findings for an internet sample. Pediatrics: $113 .$, e570-e577. http://dx.doi.org/10.1542/peds.113.6.e570

Scher, A., Epstein, R., \& Tirosh, E. (2004). Stability and changes in sleep regulation: a longitudinal study from 3 months to 3 years. International Journal of Behavioral Development: 28., (3), 268-274. http://dx.doi.org/10.1080/01650250344000505

Scher, A., Zukerman, S., \& Epstein, R. (2005). Persistent night waking and settling difficulties across the first year: early precursors of later behavioural problems? Journal of Reproductive and Infant Psychology: 23., (1), 77-88. http://dx.doi.org/10.1080/02646830512331330929

So, K., Adamnson, M. T., \& Horne, R. S. C. (2007). The use of actigraphy for assessment of the development of sleep/wake patterns in infants during the first 12 months of life. Journal of Sleep Research: 16., 181-187. http://dx.doi.org/10.1111/j.1365-2869.2007.00582.x

St James-Roberts, I., \& Plewis, I. (1996). Individual differences, daily fluctuations, and developmental changes in amounts of infant waking, fussing, crying feeding, and sleeping. Child Development: 67., 2527-2540. http://dx.doi.org/10.1111/j.1467-8624.1996.tb01872.x

Taveras, E. M., Rifas-Shiman, S. L., Oken, E., Gunderson, E. P., \& Gillman, M. W. (2008). Short sleep duration in infancy and risk of childhood overweight. Archives of Pediatrics \& Adolescent Medicine: 162., (4), 305-311. http://dx.doi.org/10.1001/archpedi.162.4.305

Teng, A., Bartle, A., Sadeh, A., \& Mindell, J. (2012). Infant and toddler sleep in Australia and New Zealand. Journal of Paediatrics and Child Health: 48., 268-273. http://dx.doi.org/10.1111/j.1440-1754.2011.02251.x

Tikotzky, L., \& Sadeh, A. (2009). Maternal sleep-related cognitions and infant sleep: a longitudinal study from pregnancy through the 1 st year. Child Development: 80., (3), 860-874. http://dx.doi.org/10.1111/j. 1467-8624.2009.01302.x

Tikotzky, L., De Marcas, G., Har-toov, J., Dollberg, S., Bar-haim, Y., \& Sadeh, A. (2010). Sleep and physical growth in infants during the first 6 months. Journal of Sleep Research: 19., (1-Part-I), 103-110. http://dx.doi.org/10.1111/j.1365-2869.2009.00772.x

Tikotzky, L., Sadeh, A., Volkovich, E., Manber, R., Meiri, G., \& Shahar, G. (2015). VII. Infant sleep development from 3 to 6 months postpartum: links with maternal sleep and paternal involvement. Monographs of the Society for Research in Child Development: 80., 107-124. http://dx.doi.org/10.1111/mono.12147

Volkovich, E., Zion, H. B., Karny, D., Meiri, G., \& Tikotzky, L. (2015). Sleep patterns of co-sleeping and solitary sleeping infants and mothers: a longitudina study: sleeping arrangements and sleep quality of infants and mothers. Sleep Medicine, http://dx.doi.org/10.1016/j.sleep.2015.08.016 (in press)

Werner, H., Molinari, L., Guyer, C., \& Jenni, O. G. (2008). Agreement rates between actigraphy, diary, and questionnaire for children's sleep patterns. Archives of Pediatrics and Adolescent Medicine: 162., (4), 350-358. http://dx.doi.org/10.1001/archpedi.162.4.350 